\title{
A repartição constitucional de competências federativas em matéria de saúde em tempos de covid-19: cada um por si e todos contra o vírus
}

Heron Abdon Souza ${ }^{1}$

\section{Resumo}

A Constituição de 1988 estabelece uma repartição de competências em matéria de saúde entre os entes federativos que orientou a edição de atos normativos federais, estaduais e municipais no enfrentamento dos efeitos das diversas matizes da crise provocada pela pandemia do novo coronavírus (SARS-CoV-2). O presente artigo busca analisar a diversidade desse arcabouço jurídico e sua repercussão na sociedade e no Poder Judiciário.

Palavras-chave: Competências; Constituição; Cooperação; COVID19; Federalismo.

\section{Abstract}

The Constitution of 1988 establishes a division of competences in health matters among the federated entities that guided the edition of federal, state and municipal normative acts in facing the effects of the different shades of the crisis caused by the pandemic of the new coronavirus

\footnotetext{
${ }^{1}$ Professor Adjunto da Universidade Federal Fluminense. Pós-Doutor em Democracia e Direitos Humanos pela Faculdade de Direito da Universidade de Coimbra.
} 
(SARS-CoV-2). This article seeks to analyze the diversity of this legal framework and its impact on society and the Judiciary.

Keywords: Competences; Constitution; Co-operation; COVID-19; Federalism.

\section{INTRODUÇÃO}

O Brasil e os demais países do mundo vêm enfrentando, nos últimos meses, as implicações sanitárias, sociais e econômicas resultantes da pandemia do novo coronavírus (SARS-CoV-2). ${ }^{2}$

Apesar de estarem diante de um "inimigo" comum (o vírus) e um objetivo comum (conter e enfrentar a pandemia), a União, os Estados, o Distrito Federal e os Municípios disputaram hegemonias institucionais esmaecendo o pacto federativo.

A partir da adoção do instrumento jurídico "quarentena", previsto no inciso II, do art. $2^{\circ}$, da Lei Federal n ${ }^{\circ} 13.979$ de 06 de fevereiro de $2020^{3}$, as medidas sanitárias restritivas/protetivas (normas infralegais) adotadas mostraram-se variadas e conflitantes entre os entes federativos.

2 WORLD HEALTH ORGANIZATION. Statement on the second meeting of the International Health Regulations (2005) Emergency Committee regarding the outbreak of novel coronavirus (2019-nCoV). Genebra, 30 jan. 2020. Disponível em <https://www.who.int/>. Acesso em 01/06/2020.

${ }^{3}$ Lei Federal n ${ }^{\circ} 13.979 / 2020$. Art. $2^{\circ}$ - Para fins do disposto nesta Lei, considera-se: I (...); e II - quarentena: restrição de atividades ou separação de pessoas suspeitas de contaminação das pessoas que não estejam doentes, ou de bagagens, contêineres, animais, meios de transporte ou mercadorias suspeitos de contaminação, de maneira a evitar a possível contaminação ou a propagação do coronavírus. Disponível em: <http://www.planalto.gov.br/ccivil_03/_ato2019-2022/2020/lei/L13979.htm >. Acesso em 04/06/2020. 
Cabe à União deter a exclusividade na contenção e enfrentamento da pandemia do novo coronavírus e a concentração administrativa para editar normas gerais sanitárias, com vigência nacional, em detrimento do federalismo cooperativo?

O presente artigo se propõe a analisar a complexa divisão constitucional de competências federativas em matéria de saúde, a amplitude e o descompasso jurídico- federativo na implementação das políticas públicas essenciais para contenção e combate à pandemia do SARS-CoV-2, os limites de cada personagem (União, os Estados, o Distrito Federal e os Municípios) e o entendimento do Supremo Tribunal Federal. ${ }^{4}$

\section{A REPARTIÇÃO CONSTITUCIONAL DE COMPETÊNCIAS EM MATÉRIA DE SAÚDE ENTRE OS ENTES FEDERATIVOS}

A Constituição de 1988 estabelece uma cooperação entre a União, os Estados, o Distrito Federal e os Municípios a partir de uma divisão de competências/responsabilidades não hierarquizadas. ${ }^{5}$

\footnotetext{
${ }^{4}$ Nesse sentido, destaca Paulo Gustavo Gonet Branco: "uma vez que não há o direito de secessão na fórmula federativa, os conflitos que venham a existir entre os Estadosmembros ou entre qualquer deles com a União necessitam ser resolvidos para a manutenção da paz e da integridade do Estado como um todo. Assumindo feição jurídica, o conflito será levado ao deslinde de uma corte nacional, prevista na Constituição, com competência para isso". (MENDES, Gilmar Ferreira; BRANCO, Paulo Gutavo Gonet. Curso de Direito Constitucional. 15. ed. São Paulo: Saraiva, 2020, p. 843)

${ }^{5}$ MORBIDELLI, Janice Helena Ferreri. Um novo pacto federativo para o Brasil. São Paulo: Celso Bastos. 1999, p. 188.
} 
A adoção do modelo do federalismo cooperativo pressupõe ${ }^{6}$ igualdade e equilíbrio perante um complexo sistema de repartição constitucional de competências entre a União, Estados, Distrito Federal e Municípios. $^{7}$

Nesse sentido, destaca-se excerto da ementa do acórdão do Recurso Extraordinário no 1.247.930-AgR/SP, julgado em 13 de março de 2020 pela $1^{\text {a }}$ Turma do Supremo Tribunal Federal, sob Relatoria do Ministro Alexandre de Moraes:

[...] 4. A Federação nasceu adotando a necessidade de um poder central, com competências suficientes para manter a união e a coesão do próprio país, garantindo-lhe, como afirmado por HAMILTON, a oportunidade máxima para consecução da paz e da liberdade contra o facciosismo e a insurreição (The Federalist papers, $\mathrm{n}^{\circ}$ IX), e permitindo à União realizar seu papel aglutinador dos diversos EstadosMembros e de equilíbrio no exercício das diversas funções constitucionais delegadas aos três poderes de Estado. 5. Durante a evolução do federalismo, passou-se da ideia de três campos de poder mutuamente exclusivos e limitadores, segundo a qual a União, os Estados e os Municípios teriam suas áreas exclusivas de autoridade, para um novo modelo federal baseado, principalmente, na cooperação, como salientado por KARL LOEWESTEIN (Teoria de la constitución. Barcelona: Ariel, 1962. p. 362). 6. O legislador constituinte de 1988, atento a essa evolução, bem como sabedor da tradição centralizadora brasileira, tanto, obviamente, nas diversas ditaduras que sofremos, quanto nos momentos de normalidade democrática, instituiu novas regras descentralizadoras na distribuição formal de

${ }^{6}$ Sobre o caráter teórico do federalismo cooperativo: “(...) a prática do federalismo sob a Constituição de 1988 tem sido bem diversa do previsto no texto constitucional. Um exemplo, consequência direta da falta de uma política nacional de desenvolvimento, é a guerra fiscal, travada entre os Estados para a atração de novas indústrias". (BERCOVICI, Gilberto. Dilemas do Estado Federal Brasileiro. Porto Alegre: Livraria do Advogado, 2004. p. 95-96).

7 SILVA, José Afonso da. Um pouco de Direito Constitucional Comparado. 1 ed. São Paulo: Malheiros, 2009, p. 98. 
competências legislativas, com base no princípio da predominância do interesse, e ampliou as hipóteses de competências concorrentes, além de fortalecer o Município como polo gerador de normas de interesse local. 7. O princípio geral que norteia a repartição de competência entre os entes componentes do Estado Federal brasileiro é o princípio da predominância do interesse, tanto para as matérias cuja definição foi preestabelecida pelo texto constitucional, quanto em termos de interpretação em hipóteses que envolvem várias e diversas matérias, como na presente Ação Direta de Inconstitucionalidade. 8. A própria Constituição Federal, portanto, presumindo de forma absoluta para algumas matérias a presença do princípio da predominância do interesse, estabeleceu, a priori, diversas competências para cada um dos entes federativos, União, Estados- Membros, Distrito Federal e Municípios, e, a partir dessas opções, pode ora acentuar maior centralização de poder, principalmente na própria União (CF, art. 22), ora permitir uma maior

descentralização nos Estados-membros e Municípios (CF, arts. 24 e 30 , inciso I) $[\ldots]^{8}$

Sobre o federalismo cooperativo, destacou o Ministro Edson Fachin (Relator) em seu voto no julgamento da ADI 5358 em 03 de agosto de 2016:

As transformações sociais mudam, por consequência, as concepções do Estado, inclusive no tocante à sua estruturação, atingindo também a repartição de competências. Determinando-se a igualdade e equilíbrio entre os entes, a Constituição ressalta a necessidade de maximização do exercício destas competências para que o Estado cumpra seu desiderato de pacificação e satisfação social. É este novo olhar que se propõe a partir da nova ordem inaugurada pela Constituição Federal de 1988. Um olhar voltado para a otimização da cooperação entre os entes federados; um olhar voltado para a maximização do conteúdo normativo dos direitos fundamentais; um olhar

8 SUPREMO TRIBUNAL FEDERAL. RE 1.247.930-AgR/SP, $1^{\mathrm{a}}$ Turma. Relator Ministro Alexandre de Moraes. Disponível em <https://stf.jusbrasil.com.br/jurisprudencia/825659809/agreg-no-recursoextraordinario-agr-re- $\quad$ 1247930-sp-sao-paulo-2010187-7220198260000/inteiro-teor825659819>. Acesso em 08/06/2020. 
voltado para o respeito e efetividade do pluralismo com marca característica de um Estado Federado. ${ }^{9}$

O princípio geral que norteia a repartição constitucional de competências entre os entes federativos é o princípio da predominância do interesse. Caberá à União as matérias de interesse nacional, aos Estados as matérias em que prevalecerem o interesse regional e aos Municípios os assuntos de interesse local. Já o Distrito Federal acumula as matérias de interesses regional e local ${ }^{10}$.

A repartição constitucional de competências federativas é classificada por Alexandre de Moraes a partir de quatro pontos básicos:

\begin{abstract}
Reserva de campos específicos de competência administrativa e legislativa: União - Poderes enumerados ( $\mathrm{CF}$, arts. 21 e 22) Estados - Poderes remanescentes $\left(\mathrm{CF}\right.$, art. $\left.25, \S 1^{\circ}\right)$ Município-Poderes enumerados (CF, art. 30) Distrito Federal - Estados + Municípios (CF, art. 32, $\S 1^{\circ}$ ) 2. Possibilidade de delegação ( $\mathrm{CF}$, art. 22, parágrafo único) - Lei complementar federal poderá autorizar os Estados a legislar sobre questões específicas das matérias de competência privativa da União. 3. Áreas comuns de atuação administrativa paralela (CF, art. 23) 4. Áreas de atuação legislativa concorrentes $\left(\mathrm{CF}\right.$, art. 24) ${ }^{11}$
\end{abstract}

Observa-se, portanto, que a Constituição Federal

${ }^{9}$ SUPREMO TRIBUNAL FEDERAL. ADI 5356. Relator Ministro Edson Fachin, Red. p/acórdão Ministro Marco Aurélio Disponível em http://portal.stf.jus.br/processos/detalhe.asp?incidente=4817597>. Acesso em: 08/06/2020.

${ }^{10}$ MORAES, Alexandre de. Direito Constitucional. 31. Ed. São Paulo: Atlas, 2015. p. 290.

${ }^{11}$ MORAES, Alexandre de. Direito Constitucional. 31 a Ed. São Paulo: Atlas, 2015. p. 318 
estruturou um sistema que combina competências exclusivas, privativas e principiológicas com competências comuns e concorrentes, buscando reconstruir o sistema federativo segundo critérios de equilíbrio ditados pela experiência histórica. ${ }^{12}$

Nesse contexto, bem averba Fernanda Dias Menezes de Almeida que a Constituição Federal estruturou

um sistema complexo em que convivem competências privativas, repartidas horizontalmente, com competências concorrentes, repartidas verticalmente, abrindo-se espaço também para a participação das ordens parciais na esfera de competências próprias da ordem central, mediante delegação. ${ }^{13}$

A repartição constitucional de competências federativas em matéria em saúde está prevista nos artigos 23 e 24 da Constituição Federal, respectivamente, competências comuns e concorrentes à União, Estados, Distrito Federal e Municípios.

Para o planejamento e execução de políticas públicas de saúde, a Constituição atribui competência comum a todos os entes federativos (art. 23, II). ${ }^{14}$

A Constituição avaliza a competência legislativa da União para a edição de normas gerais ( $\mathrm{CF}$, art. 24) mas também acolhe a competência administrativa/material concorrente de todos os entes federativos ${ }^{15}$ que,

12 SILVA, José Afonso da. Curso de Direito Constitucional Positivo. 29a Ed. São Paulo: Malheiros, 2007. p. 477.

${ }^{13}$ ALMEIDA, Fernanda Dias Menezes de. Competências na Constituição de 1988. $5^{\text {a }}$ ed., São Paulo: Altas S/A, 2010, p. 58

${ }^{14} \mathrm{CF} / 1988$, Art. 23. É competência comum da União, dos Estados, do Distrito Federal e dos Municípios: II - cuidar da saúde e assistência pública, da proteção e garantia das pessoas portadoras de deficiência.

15 Apesar do caput do art. 24 citar apenas União, Estados e Distrito Federal, os Municípios também se submetem à mesma sistemática em razão do disposto no art. 30, II, da Constituição Federal: Art. 30. Compete aos Municípios: I - [...]; II - suplementar a 
quanto aos temas do referido dispositivo, possuem competência para produzirem normas observando o disposto no $\S 1^{\circ}$ (a União tem competência para editar normas gerais), $\$ 2^{\circ}$ (na hipótese de normas gerais editadas pela União, os demais entes estão limitados a competência suplementar), $\S 3^{\circ}$ (caso não seja editada norma geral da União, os demais entes possuem competência legislativa plena para atendimento de suas peculiaridades) e $\$ 4^{\circ}$ (caso a União edite, supervenientemente, normas gerais, as normas dos demais entes que lhes for contrária serão suspensas).

A competência concorrente supõe o primado da norma de maior abrangência, ou seja, o direito/interesse nacional tem primazia sobre o direito/interesse local pois aquele seria a "expressão política máxima com vistas aos efeitos integradores sobre a nação como um todo". ${ }^{16}$

Moreira Neto destaca que há uma dificuldade "em precisar o critério distintivo do que sejam normas gerais e do que sejam normas específicas ${ }^{17}$ " e procura sintetizar as características das normas gerais:

legislação federal e a estadual no que couber. Neste sentido, asseveram Fernanda Dias Menezes de Almeida que "[...] se mostra válido entender que aos Municípios também se conferiu participação na produção normativa concorrente, em virtude do disposto no art. 30, II, que lhes dá competência para suplementar a legislação federal e estadual no que couber" (ALMEIDA, Fernanda Dias Menezes de. Comentários ao Art. 24. In: CANOTILHO, J. J. Gomes; MENDES, Gilmar Ferreira; SARLET, Ingo Wolfgang; STRECK, Lenio Luiz (coord). Comentários à Constituição do Brasil. 2. Ed. São Paulo: Saraiva, 2018, p. 810) e Ana Paula Barcellos que "[...] os Municípios não são mencionados no caput do art. 24, mas o art. 30, II, prevê que compete a eles suplementar a legislação federal e a estadual no que couber. Assim, da conjugação do art. 24 com o art. 30, II, tem-se que as competências legislativas concorrentes podem incluir todos os entes federativos: à União cabe estabelecer normas gerais, aos Estados compete a edição de normas suplementares, e os Municípios poderão ainda suplementar esses dois conjuntos normativos federal e estadual, no que couber" (BARCELLOS, Ana Paula de. Curso de Direito Constitucional, 2. ed. Rio de Janeiro: Forense, 2019, p. 252).

16 MOREIRA NETO, Diogo de Figueiredo. Competência concorrente limitada: o problema da conceituação das normas gerais. Revista de Informação Legislativa, Brasília, ano 25, n. 100, p. 130, abr.-dez. 1988. Disponível em < http://www2.senado.leg.br/bdsf/handle/id/181992>. Acesso em 04/06/2020.

17 MOREIRA NETO, Diogo de Figueiredo. Competência concorrente limitada: o problema da conceituação das normas gerais. Revista de Informação Legislativa, 
a) estabelecem princípios, diretrizes, linhas mestres e regras jurídicas;

b) não podem entrar em pormenores ou detalhes nem, muito menos, esgotar o assunto legislado;

c) devem ser regras nacionais, uniformemente aplicáveis a todos os entes públicos;

d) devem ser regras uniformes para todas as situações homogêneas;

e) só cabem quando preencham lacunas constitucionais ou disponham sobre áreas de conflito;

f) devem referir-se a questões fundamentais;

g) são limitadas, no sentido de não poderem violar a autonomia dos Estados;

h) são normas de aplicação direta. ${ }^{18}$

Concluindo que as normas gerais são:

[...] declarações principiológicas que cabe à União editar, no uso de sua competência concorrente limitada, restrita ao estabelecimento de diretrizes nacionais sobre certos assuntos, que deverão ser respeitadas pelos Estadosmembros na feitura das suas respectivas legislações, através de normas específicas e particularizantes que as detalharão, de modo que possam ser aplicadas, direta e imediatamente, às relações e situações concretas a que se destinam, em seus respectivos âmbitos políticos. ${ }^{19}$

Brasília, ano 25, n. 100, p. 140, abr.-dez. 1988. Disponível em < http://www2.senado.leg.br/bdsf/handle/id/181992>. Acesso em 04/06/2020.

${ }_{18}$ MOREIRA NETO, Diogo de Figueiredo. Competência concorrente limitada: o problema da conceituação das normas gerais. Revista de Informação Legislativa, Brasília, ano 25, n. 100, p. 149, abr.-dez. 1988. Disponível em <http://www2.senado.leg.br/bdsf/handle/id/181992>. Acesso em 04/06/2020.

19 MOREIRA NETO, Diogo de Figueiredo. Competência concorrente limitada: o problema da conceituação das normas gerais. Revista de Informação Legislativa, Brasília, ano 25, n. 100, p. 159, abr.-dez. 1988. Disponível em < http://www2.senado.leg.br/bdsf/handle/id/181992>. Acesso em 04/06/2020. 
Nesse sentido, observa Eduardo Cambi que na elaboração das normas gerais, a União desempenha atividade diversa daquela que exerce quando elabora a legislação federal (autodirigismo). Ao dispor sobre as normas gerais, o Congresso Nacional exerce o poder de prescrever normas nacionalmente uniformes, vinculantes a todos os entes federativos. ${ }^{20}$

Ainda nesse diapasão, nos dizeres de Fernanda Dias Menezes de Almeida

Parece-nos, efetivamente, que a utilização das competências concorrentes, como idealizada, atende aos desígnios de se chegar a maior descentralização, sem prejuízo da direção uniforme que se deva imprimir a certas matérias. Numa palavra, o caminho que se preferiu é potencialmente hábil a ensejar um federalismo de equilíbrio, que depende, embora, como não se desconhece, também de outras providências. ${ }^{21}$

\section{E de Raul Machado Horta}

A legislação concorrente, que amplia a competência legislativa dos Estados, retirando-a da indigência em que a deixou a pletórica legislação federal no domínio dos poderes enumerados, se incumbirá do afeiçoamento da legislação estadual às peculiaridades locais, de forma a superar a uniformização simétrica da legislação federal. A repartição concorrente cria outro ordenamento jurídico dentro do Estado Federal, o ordenamento misto, formado pela participação do titular do ordenamento central e dos titulares de ordenamentos parciais. ${ }^{22}$

${ }^{20}$ CAMBI, Eduardo. Normas gerais e fixação da competência concorrente na federação brasileira. Revista de Processo, São Paulo, v. 23, n. 92, p. 252, out-dez. 1998.

${ }^{21}$ ALMEIDA, Fernanda Dias Menezes de. Competências na Constituição de 1988. $5^{\text {a }}$ ed., São Paulo: Altas S/A, 2010, p. 61

${ }^{22}$ HORTA, Raul Machado. Direito Constitucional. $5^{\mathrm{a}}$ ed. atual. por Juliana Campos Horta. Belo Horizonte: Del Rey, 2010, p. 324. 
Coube a União, nos termos do art. 24, XII da Constituição da República $^{23}$, editar a norma geral sobre "proteção e defesa da saúde" que estabelece uma política pública nacional e dispõe sobre as medidas para enfrentamento da emergência de saúde pública decorrente do coronavírus. Trata-se da Lei Federal no 13.979, de 06 de fevereiro de 2020.

Coube aos demais entes federativos, em face do disposto no art. 24, $\S 2^{\circ}$ e art. 30, II da Constituição da República, editar legislações suplementares. Ocorre que Estados e Municípios, além do Distrito Federal, na tarefa de adaptação de suas normas específicas às normas gerais da União editaram normas sanitárias de contenção e combate à pandemia do SARS-CoV-2 que despertaram uma crise no pacto federativo. A diversidade de comandos normativos (federais, estaduais e municipais) provocou insegurança jurídica e desorientação na população (inseguranças social e sanitária).

\section{O CONFLITO DE COMPETÊNCIAS ENTRE A UNIÃO E OS ESTADOS}

Utilizando como referências as orientações gerais da Organização Mundial da Saúde, ${ }^{24}$ do Ministério da Saúde ${ }^{25}$ e da Lei Federal no 13.979, de 06 de fevereiro de 2020, os Estados editaram, a partir de março de 2020, medidas sanitárias de alto teor restritivo/protetivo de contenção e enfrentamento ao avanço da pandemia do novo coronavírus: imposição de distanciamento/isolamento social, quarentena, suspensão de atividades de

${ }^{23} \mathrm{CF}$, art. 24, XII: Art. 24. Compete à União, aos Estados e ao Distrito Federal legislar concorrentemente sobre: [...] XII - proteção e defesa da saúde.

24 WORLD HEALTH ORGANIZATION. Coronavirus disease (COVID-19) pandemic. Disponível em

<https://www.who.int/emergencies/diseases/novel-coronavirus-2019>. Acesso em $01 / 06 / 2020$.

${ }^{25}$ BRASIL. Ministério da Saúde. Coronavírus COVID 19. O que você precisa saber. Como se proteger. Disponível em <https://coronavirus.saude.gov.br/sobre-adoenca\#como-se-proteger>. Acesso em 01/06/2020. 
ensino, restrições de comércio e atividades culturais, recomendação de adoção de trabalho remoto, restrição à locomoção individual e transporte interestadual/intermunicipal e funcionamento apenas de serviços públicos e atividades consideradas essenciais. ${ }^{26}$

$\mathrm{O}$ art. $3^{\circ}$, III - somente serão permitidas as seguintes atividades, 'J': "segurança privada, bem como serviços de manutenção, segurança, conservação, cuidado e limpeza em ambientes privados de qualquer natureza, abrangendo empresas, residências, condomínios, entidades associativas e similares". 27

O Governo Federal para conter a heterogeneidade federativonormativa, criar condições jurídicas para uma concentração administrativa e deter a exclusividade na implementação de políticas públicas (edição de normas sanitárias) para contenção e enfrentamento da pandemia do novo coronavírus em detrimento da cooperação com os

26 Alguns exemplos: Estado do Rio de Janeiro: Decreto $n^{\circ} 46.980$, de 19/03/2020 (Disponível <https://pge.rj.gov.br/comum/code/MostrarArquivo.php?C=MTAyMjQ\%2C>. Acesso em 08/03/2020).

Estado

de São Paulo: Decreto $n^{\circ}$ 64.881, de 22/03/2020

(Disponível em

〈http://www.pge.sp.gov.br/acompanhe/covid/arquivo/DecretoN64881.pdf $>$. Acesso em 12/06/2020). Estado do Ceará: Decreto n ${ }^{\circ} 33.519$, de 19/03/2020. Estado do Amazonas: Decreto $\quad n^{\circ} \quad 42101, \quad$ de 23/03/2020. (Disponível em<https://diversidadeamazonica.com.br/wp-content/uploads/2020/03/DECRETO-N.42.101-DE-23-DE- MAR\%C3\%87O-DE-2020.pdf.pdf.pdf> . Acesso em 12/06/2020). Estado do Pará: Decreto no 609, de 16/03/2020. (Disponível em <http://www.pge.pa.gov.br/content/legislacoescovid19>. Acesso em 12/06/2020). Estado de Pernambuco: Decreto $n^{\circ} 48.834$, de 20/03/2020. Disponível em $<$ https://legis.alepe.pe.gov.br/texto.aspx?tiponorma=6\&numero=48834\&complemen to $=0 \&$ ano $=2020 \&$ tipo $=\& u r l$ $=>$. Acesso em 12/06/2020). 
Estados e Municípios e competências destes, editou em 20 de março de 2020 a Medida Provisória $n^{\circ} 926^{28}$, que:

a) Alterou o caput do art. $3^{\circ}$ da Lei Federal no $13.979 / 2020$ :

Art. $3^{\circ}$ - Para enfrentamento da emergência de saúde pública de importância internacional decorrente do coronavírus, as autoridades poderão adotar, no âmbito de suas competências, dentre outras, as seguintes medidas:

b) Acrescentou o $\S^{\circ}$ ao caput do art. $3^{\circ}$ da Lei Federal $n^{\circ}$ 13.979/2020: Art. $3^{\circ}, \S 8^{\circ}$ - "As medidas previstas neste artigo, quando adotadas, deverão resguardar o exercício e o funcionamento de serviços públicos e atividades essenciais."

c) Acrescentou o $\$ 9^{\circ}$ ao caput do art. $3^{\circ}$ da Lei Federal $n^{\circ}$ 13.979/2020: “Art. $3^{\circ}$, §9 - O Presidente da República disporá, mediante decreto, sobre os serviços públicos e atividades essenciais a que se referem o $\S 8^{\circ}$."

d) Acrescentou o $\$ 10$ ao caput do art. $3^{\circ}$ da Lei Federal $n^{\circ}$ 13.979/2020:

Art. $3^{\circ}, \S 10$ - As medidas a que se referem os incisos I, II e VI do caput, quando afetarem a execução de serviços públicos e atividades essenciais, inclusive as reguladas, concedidas ou autorizadas, somente poderão ser adotadas em ato específico e desde que em articulação prévia com o órgão regulador ou o Poder concedente ou autorizador.

\footnotetext{
28 Medida Provisória no 926, de 20/03/2020. Disponível em <http://www.planalto.gov.br/ccivil_03/_ato2019- 2022/2020/Mpv/mpv926.htm>. Acesso em 04/06/2020.
} 
e) Acrescentou o $\$ 11$ ao caput do art. $3^{\circ}$ da Lei Federal $n^{\circ}$ 13.979/2020:

Art. $3^{\circ}, \S 11$ - É vedada a restrição à circulação de trabalhadores que possa afetar o funcionamento de serviços públicos e atividades essenciais, definidas nos termos do disposto no $§ 9^{\circ}$, e cargas de qualquer espécie que possam acarretar desabastecimento de gêneros necessários à população.

f) Alterou a redação do inciso VI do caput do art. $3^{\circ}$ da Lei Federal no 13.979/2020:

Art. $3^{\circ}$, VI - restrição excepcional e temporária, conforme recomendação técnica e fundamentada da Agência Nacional de Vigilância Sanitária, por rodovias, portos ou aeroportos de:

a) entrada e saída do País; e

b) locomoção interestadual e intermunicipal.

Ressalte-se que:

a) Os incisos I, II e VI do caput do art. $3^{\circ}$ da Lei $n^{\circ}$ $13.979 / 2020$ vinculam-se diretamente ao inciso II do $\S 7^{\circ}$ do caput do art. $3^{\circ}$ da mesma lei:

Art. $3^{\circ}, \S 7^{\circ}$ - As medidas previstas neste artigo poderão ser adotadas: I - [...];

II - pelos gestores locais de saúde, desde que autorizados pelo Ministério da Saúde, nas hipóteses dos incisos I, II, V e VI do caput deste artigo. 
b) Os incisos I e II do caput do art. $3^{\circ}$ da Lei Federal $n^{\circ}$ 13.979/2020 não sofreram alterações em suas redações:

Art. $3^{\circ}$ - Para enfrentamento da emergência de saúde pública de importância internacional decorrente do coronavírus, as autoridades poderão adotar, no âmbito de suas competências, dentre outras, as seguintes medidas:

I - isolamento;

II - quarentena

Sobre o mesmo contexto, em 22 de março de 2020 foi editada a Medida Provisória $n^{\circ} 927{ }^{29}$ que:

a) alterou a redação do $\S 6^{\circ}$ do caput do art. $3^{\circ}$ da Lei 13.979/2020: Art. $3^{\circ}, \S 6^{\circ}$ - "Ato conjunto dos Ministros de Estado da Saúde, da Justiça e Segurança Pública e da Infraestrutura disporá sobre a medida prevista no inciso VI do caput."

b) acrescentou o $\$ 6^{\circ}$-A ao caput do art. $3^{\circ}$ da Lei $n^{\circ} 13.979 / 2020$ : Art. $3^{\circ}, \S 6^{\circ}-\mathrm{A}$ - "O ato conjunto a que se refere o $\S 6^{\circ}$ poderá estabelecer delegação de competência para a resolução dos casos nele omissos."

c) alterou a redação do $\S 6^{\circ}$ do caput do art. $3^{\circ}$ da Lei 13.979/2020: Art. $3^{\circ}, \S 6^{\circ}$ - "Ato conjunto dos Ministros de Estado da Saúde, da Justiça e Segurança Pública e da Infraestrutura disporá sobre a medida prevista no inciso VI do caput." 
d) acrescentou o $\$ 6^{\circ}$-A ao caput do art. $3^{\circ}$ da Lei $n^{\circ} 13.979 / 2020$ : Art. $3^{\circ}, \S 6^{\circ}-\mathrm{A}$ - "O ato conjunto a que se refere o $\S 6^{\circ}$ poderá estabelecer delegação de competência para a resolução dos casos nele omissos."

Foram viabilizadas as premissas legais para que o Governo Federal editasse normas sanitárias infralegais de baixo teor restritivo/protetivo com objetivo de cumprimento obrigatório em todo território nacional.

Em 20 de março de 2020 foi editado o Decreto Federal ${ }^{\circ} 10.282$ ${ }^{30}$ o qual indicara um rol de serviços públicos e atividades essenciais "indispensáveis ao atendimento das necessidades inadiáveis da comunidade, assim considerados aqueles que, se não atendidos, colocam em perigo a sobrevivência, a saúde ou a segurança da população (...)" e que deveriam ter seu exercício e funcionamento resguardados pelas "pessoas jurídicas de direito público interno, federal, estadual, distrital e municipal, e aos entes privados e às pessoas naturais." 31

Em 08 de maio de 2020, o Decreto Federal $\mathrm{n}^{\mathbf{0}} 10.344$ acrescentou o inciso LVI ao $\$ 1^{\circ}$ do caput do art. $3^{\circ}$ do Decreto $\mathrm{n}^{\mathrm{o}}$ 10.282/2020: "Art. $3^{\circ}$, LVI - salões de beleza e barbearias, obedecidas

30 Posteriormente alterado pelos Decretos $\mathrm{n}^{\circ} 10.288$, de 22/03/2020, $\mathrm{n}^{\circ} 10.292$, de 25/03/2020, no 10.329, de 28/04/2020, $\quad \mathrm{n}^{\text {o }}$

10.342 , de

$07 / 05 / 2020$

e $\quad \mathrm{n}^{\mathrm{o}} 10.344$ de $08 / 05 / 2020$. Disponível

em <http://www.planalto.gov.br/CCIVIL_03/_Ato2019-

2022/2020/Decreto/_decretos2020.htm>. Acesso em: 04/06/2020.

31 Decreto $\mathrm{n}^{\mathrm{o}}$ 10282, de 20 de março de 2020. Disponível em<http://www.planalto.gov.br/ccivil_03/_ato2019- 2022/2020/decreto/D10282.htm>. Acesso em 04/06/2020. 
as determinações do Ministério da Saúde." ${ }^{32}$ Foram incluídas como atividades essenciais e, portanto, com funcionamento permitido durante a pandemia.

Ocorre que o Governo do Estado de Sergipe, nos termos da alínea 'b', do inciso I, do art. $2^{\circ}$ do Decreto Estadual no 40.567 de 24 de março de 2020, proibira a abertura de "salão de beleza" por considerálo uma atividade não essencial. ${ }^{33}$

Um barbeiro da cidade de Itabaiana (Estado de Sergipe), inconformado com a impossibilidade de não poder trabalhar, impetrou, em 14 de maio de 2020, mandado de segurança (com pedido de liminar) no Tribunal de Justiça do Estado de Sergipe ${ }^{34}$ requerendo que não se submetesse às regras do Decreto Estadual $n^{\circ} 40.567 / 2020$ com fundamento no conflito direto com a permissibilidade prevista no Decreto Federal $\mathrm{n}^{\circ} 20.282 / 2020$ e, consequentemente, que fosse autorizado a reabrir o seu estabelecimento comercial.

O Desembargador do Tribunal de Justiça do Estado de Sergipe, Ricardo Múcio Santana de A. Lima, em 15 de maio de 2020 concedeu

32 Decreto no 10.344, de 08/05/2020. Disponível em <http://www.planalto.gov.br/ccivil_03/_ato2019- 2022/2020/decreto/D10344.htm>. Acesso em 04/06/2020.

33 Decreto $\mathrm{n}^{\mathrm{o}} 40.567$ de 24/03/2020. Disponível em <https://www.pge.se.gov.br/decretos/>. Acesso em 05/06/2020. Ressalte-se que o prazo de vigência descrito no caput do art. $2^{\circ}$ (17 de abril de 2020) foi sucessivamente prorrogado pelos Decretos $n^{\circ} 40.576$, de 16/04/2020; $n^{\circ} 40.587$, de 23/04/2020; $n^{\circ}$

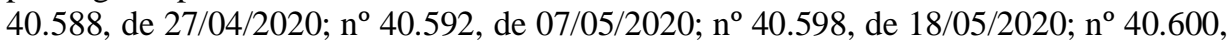
de 25/05/2020; $\mathrm{n}^{\text {o }} 40.605$, de 01/06/2020. Disponível em <https://www.pge.se.gov.br/decretos/>. Acesso em 05/06/2020.

34 TRIBUNAL DE JUSTIÇA DO ESTADO DE SERGIPE. Mandado de Segurança $\mathbf{n}^{\circ}$ 0004311- 66.2020.8.25.0000. Disponível em <https://www.tjse.jus.br/portal/consultas/consulta-processual $>$. Acesso em $06 / 06 / 2020$. 
a ordem para suspender a aplicação do Decreto Estadual no 40.567/2020 pois entendeu que

[...] o Presidente da República pode editar Decretos sobre a pandemia e os Estados e Município possuem competência concorrente, sendo certo que todas as normas federais, estaduais e municipais devem atender à razoabilidade.

Gramaticalmente falando, não podemos considerar que uma barbearia seja um salão de beleza, tanto assim é, que o Decreto presidencial refere-se aos dois estabelecimentos. Neste caso, o óbice de funcionamento poderia ser enquadrado na expressão 'comércio em geral' constante do Decreto estadual.

[...]

Ora, a partir do momento que um Decreto presidencial libera o uso de 'barbearia', os decretos estaduais e municipais só podem efetivar uma proibição que seja razoável.

Então, em casos em que a pandemia se demonstre diversa de outros locais, o decreto estadual encontra razoabilidade. Assim, por exemplo, o Estado do Ceará, que apresentou um índice de contaminação alto em comparação com os demais estados do nordeste.

Sergipe vem enfrentando a pandemia com índices normais que não justificam medidas que podem se apresentar mais nocivas que a própria pandemia, considerado o interesse social.

A abertura de uma barbearia atendendo a normas ditadas pelos organismos de saúde, em nada difere dos bancos e supermercados. Ou melhor, apresentam um movimento bem inferior e menor risco de contaminação.

Por estes argumentos, fundado no princípio da razoabilidade e considerando o Decreto Presidencial, que inseriu os salões de beleza como atividade essencial [...] DEFIRO a liminar para que o Impetrante possa desenvolver sua atividade de BARBEARIA, durante o período de restrição imposto pelo Decreto ${ }^{\circ}$ 40.567/2020 $[\ldots]$

O Estado de Sergipe ajuizou, em 18 de maio de 2020, no Supremo Tribunal Federal a Suspensão de Segurança no 5383 (com pedido de 
medida cautelar) ${ }^{35}$ destacando o potencial efeito multiplicador da decisão e a grave lesão à ordem, à economia e à saúde públicas. Sustentou, ainda, que as barbearias não poderiam ser classificadas como serviços essenciais e que o Poder Judiciário não deveria se inserir na esfera de atuação do Poder Executivo para contornar os termos de Decreto Estadual no 40.567/2020.

Em 19 de maio de 2020, o Ministro Dias Toffoli (Relator) deferiu o pedido para suspender, liminarmente, os efeitos da decisão do Tribunal de Justiça do Estado de Sergipe que concedeu a ordem para suspender a aplicação de Decreto Estadual no 40.567/2020. Aduziu o Relator que a competência da União para legislar sobre assuntos de interesse geral não afasta a incidência das normas estaduais e municipais expedidas com base na competência concorrente, devendo prevalecer aquelas de âmbito regional, quando o interesse em análise for predominantemente de cunho local. O Ministro concluiu que a abertura de estabelecimentos comerciais (barbearias), especialmente durante uma pandemia, não aparenta ser um tema de interesse nacional.

Um outro caso de descompasso normativo-federativo foi a abordagem do tema "transporte interestadual e intermunicipal" presente simultaneamente no Decreto Federal $n^{\circ} 10.282 / 2020\left(\operatorname{art} .3^{\circ}, \mathrm{V}\right){ }^{36} \mathrm{e}$ em decretos estaduais, por exemplo, no Decreto Estadual (Governo do

35 SUPREMO TRIBUNAL FEDERAL. SS 5383. Relator Ministro Presidente Dias Toffoli. Disponível

em http://www.stf.jus.br/arquivo/cms/noticiaPresidenciaStf/anexo/SS5383.pdf. Acesso em 08/06/2020.

36 Texto original do Decreto $\mathrm{n}^{\mathrm{o}} 10.282$ de 20/03/2020: art. $3^{\circ}$, V - transporte intermunicipal, interestadual e internacional de passageiros e o transporte de passageiros por táxi ou aplicativo. Nova redação dada pelo Decreto $\mathrm{n}^{\circ} 10.329$, de 28/04/2020: V - trânsito e transporte interestadual e internacional de passageiros. Disponível em $\quad$ http://www.planalto.gov.br/ccivil 03/ato20192022/2020/decreto/D10282.htm>. Acesso em 06/06/2020. 
Estado da Bahia) no 19.549 , de 18 de março de 2020 (art. 5 , I e II) ${ }^{37}$ e no Decreto Estadual (Governo do Estado do Rio de Janeiro) $n^{\circ} 46.980$, de 19 de março de 2020 (art. $4^{\circ}$, VIII e IX). ${ }^{38}$

Em 26 de março de 2020, a Confederação Nacional do Transporte propôs no Supremo Tribunal Federal a ADPF 665 (com pedido de liminar), ${ }^{39}$ Relator Ministro Luiz Fux, questionando decretos estaduais ${ }^{40}$ que determinaram o fechamento indiscriminado das divisas intermunicipais e interestaduais com o objetivo de conter os efeitos da pandemia do novo coronavírus. Alegou que as medidas ofendiam o pacto federativo pois invadiram a competência da União para legislar sobre

${ }^{37}$ Decreto $\mathrm{n}^{\circ}$ 19.549/2020. Art. $5^{\circ}$ - Ficam suspensas, pelo período de 10 (dez) dias, a partir da primeira hora do dia 20 de março de 2020, a circulação e a saída, e, a partir da nona hora do dia 20 de março de 2020, a chegada: I - de qualquer transporte coletivo intermunicipal, público e privado, rodoviário e hidroviário, nas modalidades regular, fretamento, complementar, alternativo e de vans, nos Municípios de Salvador, Feira de Santana, Porto Seguro, Prado, Lauro de Freitas, Simões Filho, Vera Cruz e Itaparica; II - de ônibus interestaduais, no território do Estado da Bahia. Disponível em < http://www.legislabahia.ba.gov.br/documentos?categoria\%5B0\%5D=2>. Acesso em $07 / 06 / 20$

${ }^{38}$ Decreto no $^{\circ} 46.980$, de 19/03/2020: art. $4^{\circ}$, VIII - a partir da Oh (zero hora) do dia 21 de março de 2020, a circulação do transporte intermunicipal de passageiros que liga a região metropolitana à cidade do Rio de Janeiro, à exceção do sistema ferroviário e aquaviário, que operarão com restrições definidas pelo governo do Estado em regramento específico, para atendimento a serviços essenciais nas operações intermunicipais entre a capital e os municípios da Região Metropolitana do Rio de Janeiro; (...) IX - a partir da Oh (zero hora) do dia 21 de março de 2020, a circulação de transporte interestadual de passageiros com origem nos seguintes Estados: São Paulo, Minas Gerais, Espírito Santo, Bahia, Distrito Federal e demais estados em que a circulação do vírus for confirmada ou situação de emergência decretada. Compete 39

SUPREMO TRIBUNAL FEDERAL. ADPF 665. Relator Ministro Luiz Fux.

Disponível em 〈http://portal.stf.jus.br/processos/detalhe.asp?incidente=5882713 > . Acesso em 07/06/2020

${ }^{40}$ Decretos dos Estados da Bahia (Decreto n ${ }^{\circ} 19.549$ de 18/03/2020), Goiás (Decreto no 9.638 de 20/03/2020), Mato Grosso (Decreto no 419 de 20/03/2020), Paraná (Decreto $n^{\circ}$ 10648 de 18/03/2020), Pernambuco (Decreto ${ }^{\circ} 48.834$ de 20/03/2020), Rio de Janeiro (Decreto $\mathrm{n}^{\circ} 46.980$ de 19/03/2020), Rio Grande do Sul (Decreto $\mathrm{n}^{\circ} 55.128$ de 19/03/2020) e Santa Catarina (Decreto n ${ }^{\circ} 525$, de 23/03/2020). 
normas gerais, como estabelecido no art. $24, \S 1^{\circ}$, da Constituição da República, e foram tomadas sem observar os critérios gerias definidos pela autoridade central competente (União) dispostos na Lei Federal $n^{\circ}$ 13.979/2020 (alterada pela Medida Provisória ${ }^{\circ}$ 926/2020) e no Decreto Federal no 10.282/2020.

\section{A Procuradoria-Geral da República manifestou-se em 30 de março de 2020:}

Cabe a todos os entes federados atuar de forma conjunta na execução de ações e serviços de vigilância epidemiológica e de controle do surto de Covid-19 (novo coronavírus), em decorrência da competência material comum delineada pelo art. 23, II, da Constituição Federal e pormenorizada pelos arts. 16 e 18 da Lei 8.080/1990. 2. Há de se dar de forma linear e coordenada entre as unidades federadas o tratamento normativo da restrição do direito de locomoção, no contexto de implementação de medidas necessárias para mitigar as consequências da pandemia de novo coronavírus no território nacional. 3. Imposição unilateral de medidas tendencialmente voltadas ao fechamento de fronteiras, por meio da restrição ao transporte coletivo de passageiros e de cargas, bem como da restrição de ingresso de pessoas de outras unidades da Federação, aparenta desbordar dos limites da competência normativa dos Estados e dos Municípios e avança sobre o campo reservado à União para legislar sobre trânsito, transporte e normas gerais de proteção da saúde (Constituição Federal, arts. 22, XI, e 24, XII e $\S 1^{\circ}$ ). 4. Perigo na demora processual decorre dos riscos de lesão a direitos fundamentais - em especial aos direitos sociais à saúde e à alimentação -, devido ao fato de os atos normativos atacados não levarem em consideração, na imposição das medidas restritivas ao transporte coletivo de passageiros e cargas, os condicionamentos previstos pela Lei federal 13.979/2020, sobretudo as exigências de certeza científica quanto à eficácia das medidas (art. $3^{\circ}, \S$ $1^{\circ}$ ), recomendação técnica da Anvisa (art. $3^{\circ}, \mathrm{VI}$, "b") e $^{\circ}$ preservação das atividades e serviços de caráter essencial (art. $3^{\circ}, \S \S 8^{\circ}$ a 11). Parecer pelo deferimento da medida cautelar. 
Os autos encontram-se conclusos ao Relator desde 14 de maio de $2020 .^{41}$

O conflito de competência entre a União e os Estados no que cerne a edição de normas sobre "locomoção/transporte interestadual e intermunicipal" na contenção dos efeitos da pandemia do SARS-CoV-2 também foi objeto da ADI 6343 (com pedido de medida cautelar ${ }^{42}$ ),proposta pelo Rede Sustentabilidade em 24 de março de 2020, Relator Ministro Marco Aurélio, argumentando que, após o Governo Federal editar a Medida Provisória $n^{\circ}$ 926/2020, que alterou a Lei $n^{\circ}$ 13.979/2020, iniciou-se uma "patente demonstração de queda de braço com os Estados" pois diversos governadores editaram decretos no sentido de combater a propagação da pandemia em seus territórios. Segundo o requerente, o Presidente da República editou a "citada medida provisória com o fim deliberado de lhe subordinar a competência constitucionalmente atribuída aos entes federados, ou seja, uma verdadeira inversão do pacto federativo". Sustentou, ainda, a presença de um "verdadeiro emaranhado de exigências com o fim único de corromper a essência do pacto federativo" ("tríplice limitação") após a edição da Medida Provisória n 927, de 22 de março de 2020:

[...] a MP 926, de 2020, trouxe a limitação de que a restrição de locomoção intermunicipal seja condicionada à recomendação técnica e fundamentada da Agência Nacional de Vigilância Sanitária, autarquia federal. Por outro ponto, pela posição topográfica dessa mesma alteração na Lei 13.979, de 2020, fica exigida a autorização do Ministério da Saúde para adotar a restrição supra. Já no

41

Informação extraída do andamento do processo eletrônico. Dis ponível em <http://portal.stf.jus.br/processos/detalhe.asp?incidente=5882713 $>$. Acesso em 15/06/2020.

42 SUPREMO TRIBUNAL FEDERAL. ADI 6343. Relator Ministro Marco Aurélio. Relator do acórdão Ministro Alexandre de Moraes. Disponívelem: $<$ http://portal.stf.jus.br/processos/detalhe.asp?incidente=5881008 $>$. Acesso em: 07/06/2020. 
que toca à MP 927, de 2020, estabelece-se para essa restrição a necessidade de disposição em ato conjunto dos Ministros de Estado da Saúde, da Justiça e Segurança Pública e da Infraestrutura.

O Requerente destacou que com a publicação da Medida Provisória $n^{\circ}$ 926/2020 a redação do inciso VI, do art. $3^{\circ}$, da Lei $n^{\circ}$ 13.979/2020 foi alterada, permanecendo seu vínculo ao disposto no inciso II, do $\$ 7^{\circ}$, do art. $3^{\circ}$ da mesma lei e ampliando a necessidade de autorização do Ministério da Saúde inclusive para "locomoção intermunicipal” (alínea 'b', do inciso VI, art. $3^{\circ}$ da Lei no 13.979/2020) ingressando, dessa forma, no âmbito de competência dos Estados. Nesse sentido foram apresentados na petição inicial os seguintes fundamentos:

a) Julgado do STF:

Os Estados-membros são competentes para explorar e regulamentar a prestação de serviços de transporte intermunicipal. (...) A prestação de transporte urbano, consubstanciando serviço público de interesse local, é matéria albergada pela competência legislativa dos Municípios, não cabendo aos Estados-membros dispor a seu respeito. [ADI 2.349, rel. min. Eros Grau, j. 31-82005, P, DJ de 14-10-2005.] = RE 549.549 AgR, rel. min. Ellen Gracie, j. 25-11-2008, $2^{\mathrm{a}}$ T, DJE de 19-12-2008.

b) Lei $12.587 / 2012$, art. 17 , I:

Art. 17. São atribuições dos Estados: I - prestar, diretamente ou por delegação ou gestão associada, os serviços de transporte público coletivo intermunicipais de caráter urbano, em conformidade com o $\S 1^{\circ}$ do art. $25 \mathrm{da}$ Constituição Federal.

c) $\mathrm{CF}$, Art. 30, V: “Art. 30. Compete aos Municípios: [...] V organizar e prestar, diretamente ou sob regime de concessão ou 
permissão, os serviços públicos de interesse local, incluído o de transporte coletivo, que tem caráter essencial."

No tocante a Medida Provisória no 927/2020, o Rede Sustentabilidade atentou que, após a sua publicação acrescentando o §6 ao caput do art. $3^{\circ}$ da Lei $n^{\circ} 13.979 / 2020$, passou-se a exigir um ato conjunto de três Ministros - Saúde, Justiça/Segurança Pública e Infraestrutura - para dispor sobre o prescrito no inciso VI do caput do art. $3^{\circ}$ da Lei $n^{\circ} 13.979 / 2020$, ingressando, mais uma vez, no âmbito de competência dos Estados no que cerne ao tema "locomoção intermunicipal".

Concluiu a requerente que, mantidas as exigências das Medidas Provisórias no 926/2020 e no 927/2020, para um Estado tratar do transporte intermunicipal em seus domínios territoriais dependeria:

1. recomendação técnica e fundamentada da Agência Nacional de Vigilância Sanitária, (2) autorização do Ministério da Saúde e (3) observar as disposições de ato conjunto dos Ministros da Saúde, da Justiça e Segurança Pública e da Infraestrutura. Um verdadeiro pandemônio burocrático com única finalidade de ceifar a autonomia dos Estados.

Ao final requereu o deferimento de medida cautelar para a suspensão: a) do trecho "e intermunicipal" da alínea 'b', do inciso VI, do artigo $3^{\circ}$ da Lei $n^{\circ} 13.979 / 2020$, conforme redação dada pela Medida Provisória $n^{\circ} 926 / 2020$; b) do $\$ 6^{\circ}$ do art. $3^{\circ}$ da Lei $n^{\circ} 13.979 / 2020$, conforme redação dada pela Medida Provisória $n^{\circ}$ 927, caso se trate de medidas adotadas por Estados e Municípios dentro de suas competências constitucionais; c) do trecho "desde que autorizados pelo Ministério da Saúde" do inciso II, do $\$ 7^{\circ}$, do art. $3^{\circ}$ da Lei $n^{\circ} 13.979 / 2020$, caso se trate de medidas adotadas por Estados e Municípios dentro de suas competências constitucionais. 
Em 06 de maio de 2020, a maioria do Supremo Tribunal Federal concedeu parcialmente a cautelar para:

[...] i) suspender parcialmente, sem redução de texto, o disposto no art. $3^{\circ}$, VI, b, e $\S \S 6^{\circ}$ e $7^{\circ}$, II, a fim de excluir estados e municípios da necessidade de autorização ou observância ao ente federal; e ii) conferir interpretação conforme aos referidos dispositivos no sentido de que as medidas neles previstas devem ser precedidas de recomendação técnica e fundamentada, devendo ainda ser resguardada a locomoção dos produtos e serviços essenciais definidos por decreto da respectiva autoridade federativa, sempre respeitadas as definições no âmbito da competência constitucional de cada ente federativo [...]

\section{O SUPREMO TRIBUNAL FEDERAL E A PANDEMIA DO FEDERALISMO COOPERATIVO}

Concomitantemente a análise individual da validade formal e material de atos normativos específicos dos entes federativos para contenção e enfrentamento da pandemia do SARS-CoV-2 ${ }^{43}$, o Supremo Tribunal Federal foi provocado a pronunciar-se numa perspectiva teleológica mais abrangente sobre o conflito constitucional de competências entre a União, Estados, Distrito Federal e Municípios na ADPF 672 e ADI 6341.

A ADPF 672 (com pedido de medida cautelar ${ }^{44}$ ) foi proposta, em 01 de abril de 2020, pelo Conselho Federal da Ordem dos Advogados do Brasil alegando que o Presidente da República praticou ações irresponsáveis e contrárias às orientações da Organização Mundial de

\footnotetext{
43 Tratado no item anterior do presente artigo: locomoção/transporte interestadual e intermunicipal; e funcionamento de barbearia/salão de beleza.

44 SUPREMO TRIBUNAL FEDERAL. ADPF 672. Relator Ministro Alexandre de Moraes. em: <http://www.stf.jus.br/arquivo/cms/noticiaNoticiaStf/anexo/ADPF672liminar.pdf $>$. Acesso em 07/06/2020.
} 
Saúde e do próprio Ministério da Saúde que indicavam o distanciamento social como instrumento de prevenção e contenção da pandemia do novo coronavírus.

Argumentou o requerente que Governadores e Prefeitos que praticam medidas de contenção e enfrentamento da pandemia - com fundamento na Lei $\mathrm{n}^{\mathrm{o}}$ 13.979/2020, art. 23, II e art. 24, XII da Constituição de República - como suspensão de aulas, recomendação de adoção de trabalho remoto, fechamento de shoppings, comércios e parques, interrupção de atividades culturais e recreativas foram criticados e censurados pelo Presidente da República que, dessa forma, violou os preceitos fundamentais do direito à vida (art. $5^{\circ}$, caput, da $\mathrm{CF}$ ), do direito à saúde (art. $6^{\circ}$, caput, e art. 196 da $\mathrm{CF}$ ), o princípio federativo (art. $1^{\circ}$, caput, da CF) e a independência e harmonia entre os Poderes (art. $2^{\circ}$ da $\mathrm{CF})$.

Em 08 de abril de 2020, o Ministro Alexandre de Moraes (Relator) asseverou que "na condução dessa crise sem precedentes recentes no Brasil e no Mundo" faz-se mister a otimização do federalismo cooperativo:

Em momentos de acentuada crise, o fortalecimento da união e a ampliação de cooperação entre os três poderes, no âmbito de todos os entes federativos, são instrumentos essenciais e imprescindíveis a serem utilizados pelas diversas lideranças em defesa do interesse público, sempre com o absoluto respeito aos mecanismos constitucionais de equilíbrio institucional e manutenção da harmonia e independência entre os poderes [...]. Lamentavelmente [...] é fato notório a grave divergência de posicionamentos entre autoridades de níveis federativos diversos e, inclusive, entre autoridades federais componentes do mesmo nível de Governo, acarretando insegurança, intranquilidade e justificado receio em toda a sociedade. [...]

A gravidade da emergência causada pela pandemia do coronavírus exige das autoridades brasileiras, em todos os 
níveis de governo, a efetivação concreta da proteção à saúde pública [...].

Decidiu o Ministro Alexandre de Moraes que as medidas tomadas pelos Governadores e Prefeitos "quanto ao funcionamento das atividades econômicas e as regras de aglomeração" devem ser respeitadas pois

Em relação à saúde e assistência pública, inclusive no tocante à organização do abastecimento alimentar, a Constituição Federal consagra, nos termos dos incisos II e IX, do artigo 23, a existência de competência administrativa comum entre União, Estados, Distrito Federal e Municípios.

Igualmente nos termos do artigo 24, XII [...] prevê competência concorrente entre União e Estados/Distrito Federal para legislar sobre proteção e defesa da saúde; permitindo, ainda, aos Municípios, nos termos do artigo 30 , inciso II [...].

\section{Concluiu o Relator pela concessão parcial da medida cautelar determinando}

[...] a efetiva observância dos artigos 23, II e IX; 24, XII; 30, II e 198, todos da Constituição Federal na aplicação da Lei 13.979/20 e dispositivos conexos, RECONHENDO E ASSEGURANDO O EXERCÍCIO DA COMPETÊNCIA CONCORRENTE DOS GOVERNOS ESTADUAIS E DISTRITAL E SUPLEMENTAR DOS GOVERNOS MUNICIPAIS, cada qual no exercício de suas atribuições e no âmbito de seus respectivos territórios, para a adoção ou manutenção de medidas restritivas legalmente permitidas durante a pandemia, tais como, a imposição de distanciamento/isolamento social, quarentena, suspensão de atividades de ensino, restrições de comércio, atividades culturais e à circulação de pessoas, entre outras; INDEPENDENTEMENTE DE SUPERVENIENCIA DE ATO

FEDERAL EM SENTIDO CONTRÁRIO, sem prejuízo da COMPETÊNCIA GERAL DA UNIÃO para estabelecer medidas restritivas em todo o território nacional, caso entenda necessário. 
A ADI 6341 (com pedido de medida cautelar) ${ }^{45}$ foi proposta, em 23 de março de 2020, pelo Partido Democrático Trabalhista alegando que a Medida Provisória ${ }^{\circ}$ 926/2020 alterou e/ou incluiu vários dispositivos ao caput do art. $3^{\circ}$ da Lei Federal $n^{\circ}$ 13.979/2020 redistribuindo às competências dos entes federativos para a adoção de providências sanitárias no enfrentamento da emergência de saúde pública decorrente do SARS-CoV-2. A inicial destacou os seguintes dispositivos/temas impugnados:

[...] a redistribuição de poderes de polícia sanitária feita pela MP $n^{\circ}$ 926/2020 na Lei Federal $n^{\circ} 13.979 / 2020$ interferiu nos contornos do regime de cooperação entre os entes federativos, pois confinou à "Presidência da República" (art. $3^{\circ}, \S \S 8^{\circ}$ e $9^{\circ}$ ) ou ao "órgão regulador ou ao Poder concedente ou autorizador" (art. $3^{\circ}, \S \S 10^{\circ}$ ) as prerrogativas de isolamento (art. $3^{\circ}$, I), quarentena (art. $3^{\circ}$, II), interdição de locomoção (art. $3^{\circ}$, VI), de serviços públicos e atividades essenciais (art. $3^{\circ}, \S 8^{\circ}$ ) e de circulação (art. $\left.3^{\circ}, \S 11\right)$.

O Requerente apontou várias inconstitucionais da Medida Provisória no 926/2020 e, por arrastamento, do Decreto Presidencial $n^{\circ}$ 10.282/2020 que detalhou o modus operandi da execução das medidas sanitárias de isolamento, quarentena, restrição de locomoção e interdição de atividades e serviços essenciais, na medida que subtraiu a competência (CF, art. 18: violação da autonomia) administrativa comum dos Estados, do Distrito Federal e dos Municípios para cuidar da saúde (CF, art. 23, II), dirigir o sistema único (CF, art. 198, I) e executar ações de vigilância sanitária e epidemiológica (CF, art. 200, II) e promoveu uma “centralização de competência na 'Presidência da República' e no 'órgão regulador ou ao Poder concedente ou autorizador' (Lei Federal $\mathrm{n}^{\mathrm{o}}$ 13.979/2020, art. $3^{\circ}, \S \S 8^{\circ}$ a 11 , com redação da MP no 926/2020)"

\footnotetext{
45 SUPREMO TRIBUNAL FEDERAL. ADI 6341. Relator Ministro Marco Aurélio.Disponível em:< http://portal.stf.jus.br/processos/detalhe.asp?incidente=5881008 $>. \quad$ Acesso em 08/06/2020.
} 
Ao final requereu o Partido Democrático Trabalhista o deferimento de medida cautelar para declarar a nulidade dos incisos I, II e VI, bem como dos $\S \S 8^{\circ}, 9^{\circ}, 10$ e 11 , todos do caput do artigo $3^{\circ}$ da Lei Federal $n^{\circ} 13.979 / 2020$, com redação dada pela MP n ${ }^{\circ} 926 / 2020$, e, por arrastamento, do Decreto ${ }^{\circ} 10.282 / 2020$

[...] pronunciando-se sua inconstitucionalidade no sentido em que conota exclusividade à União para dispor sobre a interdição de serviços públicos e atividades essenciais mediante decreto do Presidente da República (art. $3^{\circ}$,

$\S \S 8^{\circ}, 9^{\circ}$ e 11 ) - e adotar as medidas descritas nos incisos I, II e VI do caput do artigo $3^{\circ}$ da Lei Federal no $13.979 / 2020$

- "desde que em articulação prévia com o órgão regulador ou o Poder concedente ou autorizador" (art. $3^{\circ}$,

$\S \S 10)$-, resguardando-se, nos termos do artigo 18 da Constituição, a autonomia de polícia sanitária dos Estados, do Distrito Federal e dos Municípios para implementar as referidas providências, de competência administrativa comum (CF, art. 23, II; 198, I, e 200, II).

Em 24 de março de 2020, o Ministro Marco Aurélio (Relator) decidiu pela concessão da medida cautelar destacando que necessárias providências da União não afastam atos a serem praticados pelos Estados, Distrito Federal e pelos Municípios nos termos do artigo 23, inciso II da Constituição da República. Asseverou o Ministro que "O Estado garantidor dos direitos fundamentais não é apenas a União, mas também os Estados e os Municípios."46

Em 15 de abril de 2020 a medida acauteladora foi submetida ao crivo do Plenário do Supremo Tribunal Federal ${ }^{47}$ que

[...] por maioria, referendou a medida cautelar deferida pelo Ministro Marco Aurélio (Relator), acrescida de

\footnotetext{
46 SUPREMO TRIBUNAL FEDERAL. ADI 6341. Relator Ministro Marco Aurélio. Disponível em <http://www.stf.jus.br/arquivo/cms/noticiaNoticiaStf/anexo/ADI6341.pdf. > Acesso em $12 / 06 / 2020$.

47 Primeira sessão do Plenário do STF realizada inteiramente por videoconferência (Resolução 672/2020/STF)
} 
interpretação conforme à Constituição ao $\S 9^{\circ}$ do art. $3^{\circ}$ da Lei $\mathrm{n}^{\circ} 13.979$, a fim de explicitar que, preservada a atribuição de cada esfera de governo, nos termos do inciso I do art. 198 da Constituição, o Presidente da República poderá dispor, mediante decreto, sobre os serviços públicos e atividades essenciais. ${ }^{48}$

A Corte enfatizou a gravidade da atitude do Governo Federal de tentar impedir que Estados e Municípios, no âmbito de suas respectivas competências, implementassem as políticas públicas essenciais ao enfrentamento da pandemia do novo coronavírus. Asseverou que a Lei $n^{\circ}$ 13.979/2020 sobreveio da competência própria da União para legislar sobre vigilância epidemiológica., entretanto, isso não afastaria a necessidade de resguardar a competência concorrente dos demais entes federativos na tomada de providências normativas e administrativas, no exercício de suas autonomias, na execução dos serviços de saúde. ${ }^{49}$

Pertinentes as transcrições de trechos dos votos de alguns Ministros:

a) Ministro Alexandre de Moraes

Obviamente que a competência comum administrativa não significa que todos podem fazer tudo. Isso gera bagunça. Significa que a partir da predominância do interesse, a União deve editar normas de interesse nacional, os estados, regional e os municípios visando o seu interesse local. Não é possível que ao mesmo tempo a União queira ter monopólio da condução normativa da pandemia sobre estados e municípios. Isso não é razoável. Como não é

48 Primeira sessão do Plenário do STF realizada inteiramente por videoconferência (Resolução 672/2020/STF)

49 SUPREMO TRIBUNAL FEDERAL. Compilação dos Informativos n. 972 a 975. Abril de 2020. Data da divulgação 13/05/2020, p. 06. Disponível em 〈www.stf.jus.br > arquivo > cms > anexo > Informativomensaldeabrilde2020>. Acesso em 11/06/2020. 
possível que os municípios queiram se tornar repúblicas autônomas dentro do Brasil. ${ }^{50}$

b) Ministro Gilmar Mendes

c) Ministro Edson Fachin

[...] a despeito da competência da União, subsistem as competências dos Estados e Municípios para lidar com o tema. Diante do intricado e complexo regime jurídico de repartição de competências federativas, o STF tem buscado esclarecer, de forma mais didática, que é competência comum dos entes federativos a adoção de ou manutenção de medidas restritivas durante a pandemia da Covid-19. Assim, a princípio, tanto a União, quanto os Estados e os Municípios podem (e devem) adotar imposição de distanciamento social, suspensão de atividades de ensino, restrições de comércio, atividades culturais, circulação de pessoas.

$[\ldots]$

há duas lealdades que precisam ser explicitadas. Os órgãos constitucionais têm que atuar de forma leal e fiel ao texto constitucional. Além disso, eles devem reciprocamente lealdade federativa. O Presidente da República não pode atropelar competências federativas, assim como os Estados e Municípios não podem atropelar as competências da União. [...] É preciso entender nesse sentido de que há um dever recíproco de respeito e coordenação no exercício dessas competências federativas. ${ }^{51}$

[...] no âmbito do federalismo cooperativo inaugurado pela Constituição da República, a delegação de competência a um dos poderes do Estado não pode implicar, sob o ângulo material, a hierarquização dos poderes ou das esferas de Governo.

50 TRIBUNAL DE JUSTIÇA DO ESTADO DE SÃO PAULO. Comarca de Araras, $2^{\mathrm{a}}$ Vara Cível. Decisão. Processo Digital no:1002498-40.2020.8.26.0038. Disponível em: <https://www.migalhas.com.br/arquivos/2020/6/A288315ADEFB6F_ararasf lexibilizacaoquarentena.pdf $>$. Acesso em 11/06/2020.

${ }^{51}$ SUPREMO TRIBUNAL FEDERAL. ADI 6341. Relator Ministro Marco Aurélio. Voto do Ministro Gilmar Mendes. Disponível em <https://www.conjur.com.br > votogm-competencia-concorrente>. Acesso em 11/06/2020. 


\section{CONSIDERAÇÕES FINAIS}

O presente artigo tratou da repartição constitucional de competências federativas em matéria de saúde em tempos do novo coronavírus, destacando que houve um desprezo ao federalismo cooperativo na medida que foram indicados caminhos normativos diversos provocando inseguranças jurídica, social e sanitária.

Em 25 de maio de 2020 o Ministro Luís Roberto Barroso foi empossado presidente do Tribunal Superior Eleitoral. Ao final de seu discurso deixou uma reflexão: "Tem se falado que, depois da crise, haverá um novo normal. E se não voltássemos ao normal? E se fizéssemos diferente?

Essa conduta "diferente" no tocante ao pacto federativo será o estabelecimento de um diálogo institucional e republicano entre a União, os Estados, o Distrito Federal e os Municípios no sentido de que o enfrentamento da continuidade dos efeitos da pandemia do SARS-CoV2, até que uma vacina esteja disponível, seja uma meta comum e conciliável para que o debate raso do varejo político não suplante a promessa constitucional (CF, art. 196) de que a saúde de todos será garantida mediante políticas públicas com propósito na redução do risco de doenças.

\section{REFERÊNCIAS BIBLIOGRÁFICAS}

ALMEIDA, Fernanda Dias Menezes de. Comentários ao Art. 24. In: CANOTILHO, J. J. Gomes; MENDES, Gilmar Ferreira; SARLET, Ingo Wolfgang; STRECK, Lenio Luiz (coord). Comentários à Constituição do Brasil. 2. Ed. São Paulo: Saraiva, 2018. 
. Competências na Constituição de 1988. $5^{\text {a }}$ ed., São Paulo: Altas S/A, 2010.

BAHIA. Decreto no 19.549 de 18 de março de 2020. Declara Situação de Emergência em todo o território baiano, afetado por Doença Infecciosa Viral - COBRADE 1.5.1.1.0, conforme a Instrução Normativa do Ministério da Integração Nacional $n^{\circ}$ 02, de 20 de dezembro de 2016, para fins de prevenção e enfrentamento à COVID19, e dá outras providências. Disponível em < http://www.legislabahia.ba.gov.br/documentos?categoria\%5B0\%5D= 2>. Acesso em 07/06/2020.

BARCELLOS, Ana Paula de. Curso de Direito Constitucional, 2. ed. Rio de Janeiro: Forense, 2019.

BERCOVICI, Gilberto. Dilemas do Estado Federal Brasileiro. Porto Alegre: Livraria do Advogado, 2004

\section{BRASIL. Constituição da República Federativa do Brasil (1988). Disponível em \\ 〈http://www.planalto.gov.br/ccivil_03/constituicao/constituicao.htm>. Acesso em 04/06/2020.}

BRASIL. Decreto $\mathbf{n}^{\mathbf{0}} \mathbf{1 0 . 2 8 2}$, de 20 de março de 2020. Regulamenta a Lei $\mathrm{n}^{\circ} 13.979$, de 6 de fevereiro de 2020, para definir os serviços públicos e as atividades essenciais. Disponível em<http://www.planalto.gov.br/ccivil_03/_ato20192022/2020/decreto/D10282.htm>. Acesso em 04/06/2020.

BRASIL. Decreto $n^{\circ}$ 10.344, de 08 de maio de 2020. Altera o Decreto $\mathrm{n}^{\mathrm{o}} 10.282$, de 20 de março de 2020 , que regulamenta a Lei no 13.979 , de 6 de fevereiro de 2020, para definir os serviços públicos e as atividades essenciais. Disponível em <http://www.planalto.gov.br/ccivil_03/_ato20192022/2020/decreto/D10344.htm>. Acesso em 04/06/2020. 
BRASIL. Lei $\mathbf{n}^{\mathbf{0}} \mathbf{1 3 . 9 7 9}$ de 6 de fevereiro de 2020. Dispõe sobre as medidas para enfrentamento da emergência de saúde pública de importância internacional decorrente do coronavírus responsável pelo surto de 2019.

Disponível em: $<$ http://www.in.gov.br/en/web/dou/-/lei-n-13.979-de-6-defevereiro-de-2020-242078735> Acesso em 04/06/2020.

BRASIL. Medida Provisória $\mathbf{n}^{\mathbf{0}}$ 926, de 20 de março de 2020. Altera a Lei $\mathrm{n}^{\mathrm{o}} 13.979$, de 6 de fevereiro de 2020, para dispor sobre procedimentos para aquisição de bens, serviços e insumos destinados ao enfrentamento da emergência de saúde pública de importância internacional decorrente do coronavírus. Disponível em $<$ http://www.planalto.gov.br/ccivil_03/_ato20192022/2020/Mpv/mpv926.htm>. Acesso em 04/06/2020.

BRASIL. Medida Provisória $\mathbf{n}^{\circ}$ 927, de 22 de março de 2020. Dispõe sobre as medidas trabalhistas para enfrentamento do estado de calamidade pública reconhecido pelo Decreto Legislativo $\mathrm{n}^{\circ} 6$, de 20 de março de 2020, e da emergência de saúde pública de importância internacional decorrente do coronavírus (covid-19), e dá outras providências. Disponível em

$<$ http://www.planalto.gov.br/ccivil 03/ ato2019-

2022/2020/Mpv/mpv927.htm>. Acesso em 04/06/2020.

BRASIL. Ministério da Saúde. Coronavírus COVID 19. O que você precisa saber. Como se proteger. Disponível em $<$ https://coronavirus.saude.gov.br/sobre-a-doenca\#como-se- proteger>. Acesso em 01/06/2020.

CAMBI, Eduardo. Normas gerais e fixação da competência concorrente na federação brasileira. Revista de Processo, São Paulo, v. 23, n. 92, p. 244-261, out-dez. 1998.

HORTA, Raul Machado. Direito Constitucional. 5 ${ }^{\mathrm{a}}$ ed. atual. por Juliana Campos Horta. Belo Horizonte: Del Rey, 2010

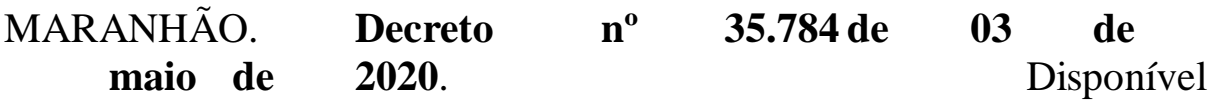


em:<https://www.ma.gov.br/agenciadenoticias/wpontent/uploads/2020/ 05/DECRETO-35.784- DE-3-DE-MAIO-DE-2020.pdf $>$. Acesso em 06/06/2020.

MENDES, Gilmar Ferreira; BRANCO, Paulo Gutavo Gonet. Curso de Direito Constitucional. 15. ed. São Paulo: Saraiva, 2020.

MORAES, Alexandre de. Direito Constitucional. $31^{\text {a }}$ Ed. São Paulo: Atlas, 2015.

MORBIDELLI, Janice Helena Ferreri. Um novo pacto federativo para o Brasil. São Paulo: Celso Bastos. 1999

MOREIRA NETO, Diogo de Figueiredo. Competência concorrente limitada: o problema da conceituação das normas gerais. Revista de Informação Legislativa, Brasília, ano 25, n. 100,p.127-162, abr.dez. 1988. Disponível em <http://www2.senado.leg.br/bdsf/handle/id/181992>. Acesso em 04/06/2020.

RIO DE JANEIRO. Decreto $\mathbf{n}^{\mathbf{0}} 46.980$ de 19 de março de 2020. Atualiza as medidas de enfrentamento da propagação decorrente do novo coronavírus (covid-19) em decorrência da situação de emergência em saúde e dá outras providências. Disponível em <https://pge.rj.gov.br/covid19/estadual/decretos>. Acesso em 06/06/2020.

SERGIPE. Decreto $n^{0}$ 40567, de 24 de março de 2020. Atualiza, consolida e estabelece novas medidas de enfrentamento e prevenção à epidemia causada pelo COVID-19 (novo Coronavírus) no Estado de Sergipe, e dá outras providências. Disponível em <https://www.pge.se.gov.br/decretos/>. Acesso em 05/06/2020.

SILVA, José Afonso da. Curso de Direito Constitucional Positivo. $29^{a}$ Ed. São Paulo: Malheiros, 2007 
. Um pouco de Direito Constitucional Comparado. 1 ed.

São Paulo: Malheiros, 2009.

SUPREMO TRIBUNAL FEDERAL. ADPF 665. Relator Ministro Luiz Fux.

$<$ http://portal.stf.jus.br/processos/detalhe.asp?incidente $=5882713>$.

Acesso em 07/06/2020.

SUPREMO TRIBUNAL FEDERAL. ADPF 672. Relator Ministro Alexandre de Moraes. Disponível em: <http://www.stf.jus.br/arquivo/cms/noticiaNoticiaStf/anexo/ADPF672 liminar.pdf>. Acesso em 07/06/2020.

SUPREMO TRIBUNAL FEDERAL. ADI 5356. Relator Ministro Edson Fachin, Red. p/acórdão Ministro Marco Aurélio. Disponível em $<$ http://portal.stf.jus.br/processos/detalhe.asp?incidente=4817597>. Acesso em 08/06/2020.

SUPREMO TRIBUNAL FEDERAL. ADI 6341. Relator Ministro Marco Aurélio. Disponível em:< http://portal.stf.jus.br/processos/detalhe.asp?incidente $=5881008>$. Acesso em 08/06/2020.

SUPREMO TRIBUNAL FEDERAL. ADI 6341. Relator Ministro Marco Aurélio. Voto do Ministro Gilmar Mendes. Disponível em <https://www.conjur.com.br > voto-gm- competencia-concorrente>. Acesso em 11/06/2020.

SUPREMO TRIBUNAL FEDERAL. ADI 6341. Relator Ministro Marco Aurélio. Voto do Ministro Edson Fachin. Disponível em <https://www.conjur.com.br $>$ voto-edson-fachin- acoes-competencia>. Acesso em 11/06/2020.

SUPREMO TRIBUNAL FEDERAL. ADI 6343. Relator Ministro Marco Aurélio. Relator do acórdão Ministro Alexandre de Moraes. Disponível em:< 
http://portal.stf.jus.br/processos/detalhe.asp?incidente=5881008>. Acesso em: 07/06/2020.

SUPREMO TRIBUNAL FEDERAL. Compilação dos Informativos n. 972 a 975. Abril de 2020. Data da divulgação 13/05/2020, p. 06. Disponível em 〈www.stf.jus.br arquivo > cms > anexo > Informativomensaldeabrilde2020>. Acesso em 11/06/2020.

SUPREMO TRIBUNAL FEDERAL. RE 1.247.930-AgR/SP, $1^{\mathrm{a}}$ Turma. Relator Ministro Alexandre de Moraes. Disponível em: <https://stf.jusbrasil.com.br/jurisprudencia/825659809/agre g-no-recurso-extraordinario-agr- re-1247930-sp-sao-paulo-20101877220198260000/inteiro-teor-825659819>. Acesso em 08/06/2020.

SUPREMO TRIBUNAL FEDERAL. SS 5383. Relator Ministro Presidente Dias Toffoli. Disponível em http://www.stf.jus.br/arquivo/cms/noticiaPresidenciaStf/anexo/SS5383 .pdf. Acesso em 08/06/2020.

TRIBUNAL DE JUSTIÇA DO ESTADO DE SÃO PAULO. Comarca de Araras, $2^{\text {a }}$ Vara

Cível. Decisão. Processo Digital no: 100249840.2020.8.26.0038. Disponível em https://www.migalhas.com.br/arquivos/2020/6/A288315ADEFB6F_ara rasflexibilizacaoquar entena.pdf $>$. Acesso em 11/06/2020.

TRIBUNAL DE JUSTIÇA DO ESTADO DE SERGIPE. Mandado de Segurança $n^{\mathbf{0}}$ 0004311-66.2020.8.25.0000. Disponível em: <https://www.tjse.jus.br/portal/consultas/consulta-processual >. Acesso em 06/06/2020.

TRIBUNAL SUPERIOR ELEITORAL Discurso de posse do Ministro Luís Roberto Barroso, Presidente do Tribunal Superior Eleitoral, Brasília, 25 de maio de 2020. Disponível em <http://www.tse.jus.br/imprensa/noticias-tse/arquivos/discursode-posse-ministro-luis-roberto-barroso-25-052020/rybena_pdf?file=http://www.tse.jus.br/imprensa/noticias- 
tse/arquivos/discurso-de-posse-ministro-luis-roberto-barroso-25-052020/at_download/file>. Acesso em 10/06/2020.

WORLD HEALTH ORGANIZATION. Statement on the second meeting of the International Health Regulations (2005) Emergency Committee regarding the outbreak of novel coronavirus (2019nCoV). Genebra, 30 jan. 2020. Disponível em <https://www.who.int/>. Acesso em 01/06/2020.

. Coronavirus disease (COVID-19) pandemic. Disponível em <https://www.who.int/emergencies/diseases/novel-coronavirus-2019>. Acesso em 01/06/2020. 